\title{
Spatial Reading, Territorial Signs, and the Clamour of Occupation
}

\section{Timothy Laurie and Peter Nyhuis Torres}

Introduction

This chapter examines the notion of reading in relation to space and place, and develops an ethics of reading from engagement with Krim Benterrak, Stephen Muecke and Paddy Roe's Reading the Country: Introduction to Nomadology. ${ }^{1}$ In the context of settler colonial Australia, ongoing practices of what Aileen Moreton-Robinson calls the 'logics of white possession' shape the ways that everyday social practices become readable in relation to Indigenous and non-Indigenous histories and communities. ${ }^{2}$ Settler colonial society teaches non-Indigenous Australians to treat Australian spaces as incapable of sustaining Indigenous bodies and meanings. Among these spaces, public beaches and memorial statues have become particularly charged sites of investment for non-Indigenous communities, ${ }^{3}$ but our focus in the latter part of this chapter will be the 'booing' of Australian Rules Football player Adam Goodes, an Andyamathanha and Narungga man, on the racialised space of the football field.

We begin this investigation through an encounter with Reading the Country. If we had spotted its spine in a library, we would have guessed that Reading the Country offered some comments on the poetics of pastoral landscapes. But then the subtitle, Introduction to Nomadology, contained a strong whiff of French philosophers Gilles Deleuze and Félix Guattari. Maybe this was a primer on A Thousand Plateaus (1980) 
or a survey of its acolytes. So, which was it: pastorals or philosophy?

Krim, Stephen and Paddy didn't do either of these thingsor at least, not quite. They went for a walk. Krim, Stephen and Paddy walk across the Roebuck Plains, lands of the Yawuru people, located near Broome in the Kimberley region of Western Australia. Going for a walk is a wonderful way to think about reading: one can pause, meander, backtrack or walk in circles. These walkerly authors proliferate textual forms-essays, songs, photographs, paintings, conversations and a chaos of typesetting styles. The words of Indigenous custodians of country, geologists and anthropologists sit across the page from paintings, photographs and drawings. These are not seats of judgement and these words do not quarrel. Country is powerful enough to draw so many other actors into relation, and to make each readable to the other. The first definition of reading in Reading the Country is given as follows:

Reading is not a perfectly natural activity which once mastered becomes automatic. A friend, Ian Hunter, once said that reading was somewhere between breathing and judging. Breathing is an automatic and natural activity most of the time, and judging, as in courts or beauty contests, is a highly social activity; it is so charged with social or cultural meaning that there is nothing natural about it. In spite of the years of training taken to achieve fluency in the skill of reading, it is largely taken for granted as an activity which enables one to see the meanings behind words straightaway. ${ }^{4}$

The above quotation belongs to a friend. In the very moment when reading is being defined, and where we would expect the source to be something read, Reading the Country offers us something heard. To repeat the operation, Peter Nyhuis Torres once mentioned Ian Hunter's definition of reading to a friend, Justin Clemens, who remarked that breath and judgement could be taken as classical symbols of life and death, respectively. One can give 'the breath of life' or hand down 'the word of judgement', and readings can vacillate 
between the two. Reading is intimately bound up with the social and genealogical aspects of cultural inheritance: what sort of reading work is required to keep ancestors in living memory? Or to borrow a phrase used by Muecke, itself borrowed from David Mowaljarlai, how can everything be kept alive in its place? ${ }^{5}$

\section{Critical reading and spatial reading}

When making or arranging socially recognised signs, individuals do not control the scope of social meanings that their signs may subsequently produce. Indeed, even those with a professional relationship to sign-making-such as authors or directors - may find their own connections to signs churned by collective processes of re-interpretation. For this reason, many literary critics have learned to become sceptical about reverential attachments toward authors. One dominant expression of this scepticism is known as critique. The Critic identifies a gap between what a text says it is doing and what it is actually doing, such that 'what a text means lies in what it does not say, which can then be used to rewrite the text in terms of a master code'. 6 Deep social conflicts give rise to signs as surface effects that deceive and obfuscate, like coils of smoke billowing from a fire. Authorial names are surface effects of this sort. Don't be fooled by signs, says the Critic, the smoke gets in your eyes.

The public performance of the academic habitus in the humanities and social sciences. Affective registers such as joy and relief are often considered less rewarding than indictment and indignation. Unfortunately, like the Hollywood film noir, the pursuit of villainous texts often focuses attention on the skills of the detective, rather than on the wellbeing of those most affected by the crime. But there is a further irony here. Rita Felski notes that the contemporary dissatisfaction with the moral piety of the Critic can lead to its own cycles of shaming, such that criticism itself becomes a new object of suspicion. This feels like a suitable noir double-cross: it is always possible to show that even the most pious and vigilant Critics may be obfuscating, whether consciously or unconsciously, hidden motives linked to their social and institutional situation. How do we avoid 'falling back into the 
register of explanation-as-accusation, where accounting for the social causes of something serves as a means of downgrading it'?7 One exit from this cycle is offered by Paul Ricoeur:

By reading we can prolong and reinforce the suspense that affects the text's reference to a surrounding world and to the audience of speaking subjects: that is the explanatory attitude. But we can also lift the suspense and fulfil the text in present speech. It is this second attitude that is the real aim of reading ... If reading is possible, it is indeed because the text is not closed in on itself but opens out onto other things. To read is, on any hypothesis, to conjoin a new discourse to the discourse of the text. ${ }^{8}$

For Ricoeur, readings follow from the affordances of the text, rather than any 'abstract physical property' of texts. An affordance is an arrangement or assembly of capabilities that allows readers to think and do things. Simone Weil expresses this attitude in the following way:

For the sailor, the experienced captain, whose ship has in a sense become like an extension of his [sic] body, the ship is a tool for reading the storm, and he reads it quite differently than the passenger. Where the passenger reads chaos, unlimited danger, fear, the captain reads necessities, limited dangers, the means of escape from the storm, a duty to act courageously and honourably. ${ }^{9}$

Ricoeur and Weil point toward a generative aspect of reading as the excitation, rather than the extraction, of textual meanings. For Ricoeur, this excitation has an inward aspect: in reading others' texts, we activate our own situations and intentions, in keeping with religious practices of hermeneutical reading. Weil is more closely aligned with cultural studies accounts of readers as doers and makers, wanderers and adventurers. The calling card of cultural studies' early interventions into literary criticism was the valuation of ordinary, everyday and habitual reading practices. Readers of romantic fiction, viewers of television soap operas and shoppers in malls became playful participants in the semiotic games of 
authors, directors and architects. ${ }^{10}$ This broad shift toward reading as an activity has turned on the meanings attached to the notion of reception.

Reception has been a key term for many of those unsatisfied with either reverential or critical approaches to reading texts. But what is a reception? Consider three shared features of two buildings that have receptions: hospitals and hotels. First, the reception is unlike the rest of the building. The reception to a hospital should not display donated organs, and the reception to a hotel should never have a bed. There are meanings specific to transitional thresholds, places of welcome, and the interfaces between insides and outsides (Gerard Genette calls these the 'paratexts'). ${ }^{11}$ Second, the reception is received as it receives us. We must work out which questions to ask and which may be asked of us. Third and most importantly, receptions distribute itineraries, shaping what the building becomes for the person moving through it. Every hotel is many hotels and every hospital is many hospitals. The ideas we form of these spaces involve mixtures of remembering and forgetting, anticipation and disappointment. Like a pedestrian navigating the corridors of an unknown building, readings produce a new map of existing terrain.

The study of reception can restore a sense of reading as a creative and embodied activity. This corporeality is easily lost in the Saussurean tradition of semiology, but can be readily identified both in historical accounts of reading practices, and in contemporary approaches to pedagogy within particular Indigenous Australian communities. Alberto Manguel's The History of Reading imagines ancient Assyrian libraries as a cacophony of very public readings, where the ability to read without making a sound or moving one's lips was seen as deeply peculiar. Unspaced and unpunctuated manuscripts were read aloud in groups and marks on the page were intended to represent speech sounds like notes on sheet music. ${ }^{12}$ Texts were one half of a conversation separated in time and space, and the written letters functioned as prompts for an actor, enabling readers to perform aloud the part of the absent author. ${ }^{13}$ Moreover, the construction of social worlds around reading that acknowledge the space of reception can be important for developing alternative pedagogies around 
reading practices. In a research project around educators in Yolyu communities of Arnhem Land (located in the northeastern corner of the Northern Territory), Melodie Bat and Sue Shore describe the significant gap between pedagogical norms promoted by the Australian Institute for Teaching and School Leadership, and what Bat and Shore call the 'grey literatures' (papers, speeches, resentations, reports) that circulate among teachers in remote Aboriginal communities. ${ }^{14}$ These literatures include an array of practical pedagogies developed to mediate between balanda (European) knowledges and literacies, a compulsory part of primary and secondary curricula, and Yolnu knowledges and literacies, which ground learning practices in the inherited and living expertise of Aboriginal communities. Bat and Shore draw attention to 'twoway' or 'both-ways' learning as a means for students to position themselves vis a vis contrasting models of education, and cite a spatial figure used by Yolyu people, that of the Ganma: 'the lagoon where the salt water and the fresh water intermingle'. ${ }^{15}$ Spatial thinking replaces oppositions with immersions. The body knows that fresh water and salt water can mix, and a simple test is to swim in the Ganma. This reorientation toward the materiality of knowledge as divided without hierarchy can perform important work in teaching spaces:

Water is often taken to represent knowledge in Yolyu Philosophy. What we see happening in the school is a process of knowledge production where we have two different cultures, Balanda and Yolyu, working together. Both cultures need to be presented in a way where each one is preserved and respected. ${ }^{16}$

The work of reading, either alone or with others, involves imagining the space one moves through when opening the text 'out onto other things', as Ricoeur earlier suggested. Spatial imaginaries offer resources walking around the metaphysical logics of identity and opposition. Seemingly incompatible categories - hot and cold, modernity and tradition, death and life - can be rearticulated as aboves and belows, heres and theres, nows and laters. Space always happens in the in-between. Travellers know that even the horizon, which 
appears to bind space in every direction, is just another space in-between other horizons.

In Reading the Country, Paddy Roe reads the country by moving through it - his reception is immediately an itinerary. Roe points out the spot where the yungurugu was driven out by a maban, ${ }^{17}$ or where a woman turned into a hill and the men who tried to touch her turned into the brolgas now pecking at the ground. ${ }^{18}$ Roebuck Plains works as a kind of memory palace, with intellectual treasures stored away in its folds. ${ }^{19}$ Land remembers its histories and provides an organic architecture for thinking through past events. Pursuing a similar trajectory, educator Coral Oomera Edwards enjoins children to develop friendly relations with the places they inhabit, to address a favoured campsite on approach ('Hello, only us mob coming up, OK if we camp here again?') or introduce themselves to their new classroom at the start of the school year ('Hello, my name is Timmy, is it OK if I spend a year with you here?'). ${ }^{20}$ Children treat country as a dear relative, paying visits, making sure it's healthy and trying to work out what it's been up to lately. Edwards proposes simple rituals for the children: 'to perform a little ceremony, to change each time they enter a place, to modify their behaviour at the threshold'. ${ }^{21}$ If stories are remembered through the places they inhabit, custodianship of a text hangs crucially on custodianship of country, and a narrative which unfolds across many places - such as one about travelling mythological beings - require telling by many speakers. ${ }^{22}$

In keeping with the lively orientation of Reading the Country, we have written about empowering and creative emplacements of reading. But there can also be a violence to place-making, and to the imposition of territorial signs upon places with pre-existing meanings. 'For the nomad,' write the authors of Reading the Country, 'Australia is still not divided into eight "states" or territories, it is crisscrossed with tracks. The smooth space of these invisible and secret tracks has been violently assaulted by the public chequerboard grid of the states.'23 Colonists in Australia have not simply claimed pre-existing territorial formations for their own; they have also attempted to destroy nomadic modes of organisation and mobility, and to re-territorialise space in ways that 
accommodate distinctly European practices of state-based governance. ${ }^{24}$ In the European construction of 'Melbourne', for example, the 'street grid was a disciplining spatial formation vital to the colonizing process'. ${ }^{25}$

The racialised management and appropriation of spaces continues to profoundly shape Aboriginal and non-Aboriginal capacities for movement through country. For example, in the wake of the Northern Territory National Emergency Response Act in 2007 (also known as the Northern Territory Intervention), the Australian government's legalised co-option of Aboriginal lands for mining interests pushed dispossessed Aboriginal people into townships and rural centres such as Darwin and Alice Springs. Displaced people faced a choice: either become permanently mobile to slip past the nets of vagrancy laws or navigate highly discriminatory housing markets. ${ }^{26}$ Aboriginal presence on ancestral land was disparaged as an unnecessary 'lifestyle choice' in 2015 by then Australian Prime Minister, Tony Abbott, ${ }^{27}$ and in Western Australia, several sacred sites (including the Burrup Peninsula and Murujuga on the Dampier Archipelago) have been deregistered from official heritage status because they are not visited more than once a year, or so the state government claims. ${ }^{28}$ Indigenous communities in Western Australia also continue to face housing policies and policing practices that enforce a White Australian understanding of the absolute differences between 'Aboriginal' and 'nonAboriginal' space, and between 'traditional' itinerant peoples and 'modern' settler communities. ${ }^{29}$ The quotidian exercise of spatial violence to police Indigenous bodies provides the backdrop for more spectacular acts of settler violence, such as the destruction of the Oombulgurri Community in the eastern Kimberley. ${ }^{30}$ In the final section of this chapter, we want to examine the ways that one highly visible space in Australia has come to be read as a 'non-Indigenous' space, and how this reading produces Indigenous bodies as out-of-place. This space is the football field.

\section{The clamour of occupation}

Reading the Country does not offer a critical theory of racial politics, but it does tell us a great deal about practices of placemaking and the circumstances through which 'race' acquires 
social and geographical meanings. The distinction between nomadic organisation and colonial organisation, for example, allows a distinction between the participatory, inclusive and spiritual connections to country often formed by Aboriginal and Torres Strait Islander communities, and the possessive, exclusive and accumulative modes of land ownership associated with British colonisation. In contrast to the metropolitan 'distribution of things in parallel lines', the 'nomad does not try to appropriate the territory, there is no sense of enclosing it and measuring it as did the early surveyors'. ${ }^{31}$ However, Reading the Country avoids characterising nomadism in terms of cultural holism, for this would still presume that 'whole races or communities can be designated or defined as being of a certain sort'. ${ }^{32}$ Nomadism might better be understood as a 'counterstrategy' that can be linked to 'any struggle for survival'. ${ }^{33}$ Here, Benterrak, Muecke and Roe introduce a further twist: there is a nomadism peculiar to the state. For example, the political lobby trades in 'favours and secrets, always mobilised towards specific tasks', and rather than establishing a clear hierarchy through territorial markings, the lobby 'works with a secret solidarity, a fraternity in which each person is on the same level, and which can go underground at any time'. ${ }^{34}$ Racialisation in Australia may take place within the territorial frames of the colonial state, but its itineraries of communication may more closely resemble the 'horizontal' and 'dispersed' movements of the lobby. ${ }^{35}$ The ostracisation of Australian Football League (AFL) player Adam Goodes provides an example of a nomadic practice that sustains, but does not coincide neatly with, the racial organisation of the settler colonial state.

AFL shares its history between Gaelic football and an Australian Indigenous game Marngrook belonging to the Gunditjmara people from Western Victoria, and it currently has significant involvement from Indigenous players around Australia. ${ }^{36}$ Adam Goodes is an Andyamathanha and Narungga man who belongs to a family marked by the history of Australia's Stolen Generations and has been a player for the Sydney Swans since 1999. ${ }^{37} \mathrm{He}$ has also been awarded the Brownlow Medal (for fairest and best player) twice, and was the 2014 Australian of the Year. In a 2013 match at the Melbourne Cricket Ground (MCG), a 13-year old Collingwood 
supporter called Goodes an 'ape' from the sidelines, and Goodes requested she be removed from the stadium. After this, a bristle of backlash followed. Merely days later, prominent Australian media personality and president of the Collingwood football team, Eddie McGuire, suggested on radio that Goodes might be useful in promotions for a King Kong production. Behind the apologies and press conferences that followed came a creeping noise of discontent fuelled by tabloid pieces about political correctness run amok. Then came the boo.

In May 2015, after kicking a goal to cap off a devastating win against Melbourne-based team Carlton at the Sydney Cricket Ground (SCG), Goodes performed a war dance. He moved in a syncopated stride toward the field barrier and completed the gesture by emulating the throwing of a boomerang. The move was developed for an underage Indigenous AFL squad the Flying Boomerangs, and intended to signal the notions of 'strong', 'fast' and 'hunting'. ${ }^{38}$ Indigenous bodies are rarely seen in absolute control of a public space on Australian television, and some Australian viewers read Goodes's athletic body as expressing confidence, drama and humour. Among those Carlton fans initially caught on camera, some were laughing - and many continued jeering. One energetic participant leant against the barricades to extend a stream of abuse at Goodes. Goodes was quickly scolded by Eddie McGuire for 'running straight towards a group of fans in an aggressive manner' and for not giving fans ample 'warning'. ${ }^{39}$ (We should note in passing that it is not uncommon for those who make territorial claims to exaggerate their own vulnerability, in order to represent 'difference' as a sign of aggression from without. ${ }^{40}$ In the following games the abuse acquired a more global dimension. Each time Goodes touched the ball the 'ooo' would surge. The boo transcended player rivalries, team rivalries, metropolitan rivalries. Despite strong defence of Goodes from senior AFL spokespeople, the boo continued. In an interview, Goodes asked, 'If we're telling our people out there that you can't represent your culture or represent where you come from, in around specifically acknowledging Aboriginal and Torres Strait Islander people, what are we saying?'41 Goodes took leave in August 2015, and when he returned, the boo rebooted. 'To Adam's ears,' wrote Wiradjuri journalist 
Stan Grant, 'the ears of so many Indigenous people, these boos are a howl of humiliation. A howl that echoes across two centuries of invasion, dispossession and suffering.' ${ }^{2}$

The boo was a clamour of occupation that posited Aboriginality as the problem and its disappearance as the solution. This was not without precedent. In the 1990s, Indigenous footballers Nicky Winmar and Michael Long both experienced racial abuse from other players and fans, leading eventually to an anti-racism clause built into the AFL Vilification and Discrimination Policy. Such clauses are ill equipped to tackle the white noise of the anonymous boo. Reflecting on the earlier Winmar and Long incidents, David McNeill notes 'Aboriginal footballers who have the courage to speak out against racism on the football field ... are somehow guilty of a kind of ingratitude'. ${ }^{43}$ Rather than confirming the myth of meritocracy by embodying the 'role model' who has overcome prejudice and obstacles to success, Goodes directly invoked his Andyamathanha and Narungga identities and made visible the political contest over space and sovereignty in Australia. One person Tweeted: 'My dislike of \#AdamGoodes has nothing to do with his race, it has to do with his attitude and his sense of entitlement.' 44 Goodes could no longer be read, by non-Indigenous audiences, as a mere asset to a domain safely possessed by white Australia. Goodes' boomerang throw invited a re-reading of the football field as an Indigenous space-or, perhaps more precisely, as a space, which Indigenous communities may inhabit as sovereign agents not beholden to approval from non-Indigenous Australians.

We seem to have detoured from the consideration of specific places invited by Reading the Country. Discussion of Goodes' symbolic significance elides the differences between football stadiums and audiences-the Melbourne Cricket Ground, the Brisbane Cricket Ground (also known as the Gabba), Perth Stadium, and so on. Sporting grounds are not neutral spaces in Australia; in many cases, they have been built in spaces previously used for gatherings by Indigenous communities. ${ }^{45}$ But Reading the Country also points toward the logic of space introduced by the state. The 'public chequerboard grid of the states' fabricates an isomorphism between places. To read the booing crowd is to leap across synchronic spaces flung across 
the continent. The boo is relayed from city to city as booers in Melbourne become booers in Perth become booers in Brisbane. The culmination of such relays is what Ghassan Hage calls the fantasy of a national space. ${ }^{46}$ Nationalists come to experience discrete practices as metonymic for national belonging or national governance, and the persons who move into these national spaces are treated as objects to be governed by a national will. ${ }^{47}$ In this context, consider this description of crowds given in Reading the Country and drawn from Elias Canetti:

[The crowd] had a power beyond that of its individual members and a logic of movement (sticking together and 'swarming') which can get things done in ways which overthrow 'proper channels' and 'standard procedures.' The collective will of a crowd demonstrates its symbolic right to occupy a space in which to live... ${ }^{48}$

The booing of Adam Goodes expressed a violence of settler colonial occupancy oriented toward a national scene. By walling the football stadium with noise, booers told the successful Indigenous man 'to stay in his place'. ${ }^{49}$

The crowd appears to be opposed to the lobby group. The crowd gathers in public, and works through disorderly movements of mimicry, affinity, and fleeting sentiment. By contrast, the lobby produces serial effects in private spaces through favours, debts, and alliances. But these two movements can coincide. When Reading the Country identifies a nomadism in the state, it points toward a mixture of two distinct orders of power: a state that seeks to measure, distribute and govern, and an unwieldy formation of interest groups that churn through the state with anti-state tactics. By invoking the lobby group as a nomadism within the state, Reading the Country points toward a mode of disorderly violence that nevertheless contributes toward, and aligns itself with, the orderly violence of the state itself. The serial techniques of the lobby group, its tactical gossip and its hidden fraternities, can produce thresholds of action without claiming a leader or purpose. Booers would regularly claim an individual dislike for Goodes, but never claim belonging to a political project. The booing of Adam Goodes was a systemic practice of serialised violence that 
operated through the disavowal of its serial character. Power can work by multiplying the spaces available for not-knowing and extending one's alliances to other not-knowers. The booing of Adam Goodes involved a lobby of not-knowers to complete the nationalist project of keeping Indigenous bodies 'in their place'. In relation to Goodes's dance, Eddie McGuire stated that '[we've] never seen that [celebration] before and I don't think we ever want to see it again to be perfectly honest, regardless of what it is. ${ }^{50}$ How often will the same speaker who desires not to know later cry that 'we did not know'?51

\section{Conclusion}

What use is the concept of reading? How do we decide which things are readable and which are not? We have drawn on Reading the Country as an invitation toward reading as a spatial practice. Krim Benterrak, Stephen Muecke and Paddy Roe enjoin us to trace the movement of signs as lively expressions of place-based histories. We have suggested some of the intellectual and political potential of Indigenous Australian concepts of country in treating space as kin, friend, interlocutor and historical archive. At the same time, the cultural politics of place involves a struggle over the signs of political identity and intentionality. 'I'm not reading you', says the booer in the football stadium, 'so don't read me.' Scholars are well-equipped to read the ideologies of power, but we are often less prepared for cacophony, confusion and noise. ${ }^{52} \mathrm{By}$ 'introducing' nomadology as a complex interplay between nomadic space and the space of the state, Reading the Country points toward the combination of powers that produce the clamour of occupation. Noise is simply one way to silence the voices and bodies that call into question that occupation.

\section{Acknowledgments}

We would like to acknowledge that this chapter was written on Aboriginal country, and we wish to thank and acknowledge the Wurundjeri people of the Kulin nation and their country for making it possible for us to present a version of this research in Melbourne. We pay our respects to their elders, past present and future. We would also like to thank Philip Morrissey for the opportunity to be a part of the Reading the Country: Thirty Years On Festival, and Marion Campbell, Chris Healy and Ann Standish for their ongoing support and patience in the preparation of this chapter. 


\section{Notes}

Krim Benterrak, Stephen Muecke and Paddy Roe, Reading the Country: Introduction to Nomadology, re.press, Melbourne, 2014 [1984]. Aileen Moreton-Robinson, The White Possessive: Property, Power, and Indigenous Sovereignty, University of Minnesota Press, Minnesota, 2015, p. xiii. Aileen Moreton-Robinson and Fiona Nicoll, 'We Shall Fight Them on the Beaches: Protesting Cultures of White Possession', Journal of Australian Studies, vol. 30, no. 89, 2006, pp. 149-6o; Tracey Banivanua Mar, 'Settler-Colonial Landscapes and Narratives of Possession', Arena Journal, no. 37/38, 2012, pp. 176-98.

4 Benterrak, Muecke and Roe, p. 16, emphasis in original.

5 Stephen Muecke, 'Motorcycles, Snails, Latour: Criticism Without Judgement', Cultural Studies Review, vol. 18, no. 1, 2012, pp. 40-58, p. 42.

6 Stephen Best and Sharon Marcus, 'Surface Reading: An Introduction', Representations, vol. 108, no. 1, 2009, pp. 1-21, p. 5; Eve Kosofksy Sedgwick, 'Paranoid Reading and Reparative Reading, Or, You're So Paranoid, You Probably Think This Essay Is About You', in Touching Feeling: Affect, Pedagogy, Performativity, Duke University Press, Durham \& London, 2003.

Rita Felski, The Limits of Critique, University of Chicago Press, Chicago and London, 2015, p. 23.

8 Paul Ricoeur, From Text to Action: Essays in Hermeneutics, II, trans. Kathleen Blamey and John B. Thompson, Continuum, London, 2008, p. 114. Simone Weil, 'Essay on the Notion of Reading', Philosophical Investigations, vol. 13, no. 4, 1990, pp. 297-303, pp. 301-2.

10 See Ien Ang, 'Culture and Communication: Towards an Ethnographic Critique of Media Consumption in the Transnational Media System', European Journal of Communication, no. 5, 1990, pp. 239-6o; Meaghan Morris, 'Things To Do with Shopping Centres', Too Soon Too Late: History in Popular Culture, Indiana University Press Bloomington, 1998, pp. 64-92 and Janice A. Radway, Reading the Romance: Women, Patriarchy, and Popular Literature, University of North Carolina Press, Chapel Hill and London, 1991 [1984], respectively.

11 Gerard Genette, Paratexts: Thresholds of Interpretation, trans. Jane E. Lewin, Cambridge University Press, Cambridge, 1987. Alberto Manguel, A History of Reading, Penguin, Middlesex, UK, 1996, p. 59.

13 Ibid., p. 51.

14 Melodie Bat and Sue Shore, 'Listening Differently: An Exploration of Grey Literature About Aboriginal Teacher Education in the Top End of the Northern Territory', in Pathways for Yolyu Teachers: Rethinking Initial Teacher Education on Country, School of Education, Charles Darwin University, Darwin, 2013. Bat and Shore, p. 9. This figure was also used by Yolnu rock group Yothu Yindi in their 1991 hit 'Treaty'. See Jill Stubington and Peter Dunbar-Hall, 'Yothu Yindi's

“Treaty”: Ganma in Music', Popular Music, vol. 13, no. 3, 1994, pp. 243-59. Marika quoted in Bat and Shore, p. 9.

17 Benterrak, Muecke and Roe, p. 57.

18 Ibid., p. 176.

19 Frances A. Yates, The Art of Memory, Penguin Books, Middlesex, UK, 1966, p. 2.

20 Coral Oomera Edwards, quoted in Stephen Muecke, Ancient and Modern: Time, Culture, and Indigenous Philosophy, University of New South Wales Press, Sydney, 2004, p. 69.

21 Ibid.

22 Stephen Muecke, Textual Spaces: Aboriginality and Cultural Studies, New South Wales University Press, Sydney, 1992, p. 89; Dorothea Hoffmann, 'Moving through Space and (Not?) Time: North Australian Dreamtime Narratives', 
in Farzana Gounder (ed.), Narrative and Identity Construction in the Pacific Islands, John Benjamins Publishing Co., Amsterdam, pp.15-36.

23 Benterrak, Muecke and Roe, p. 242.

24 This theme is explored throughout Moreton-Robinson.

25 Nadia Rhook, “The Chief Chinese interpreter" Charles Hodges: Mapping the Aurality of Race and Governance in Colonial Melbourne', Postcolonial Studies, vol. 18, no. 1, 2015, pp. 1-18, p. 3.

26 Tess Lea, Martin Young, Francis Markham, Catherine Holmes and Bruce Doran, 'Being Moved (On): The Biopolitics of Walking in Australia's Frontier Towns', Radical History Review, no. 114, 2012, pp. 139-63; Liam Grealy, 'Paperless Arrests as Preventive Detention: Motion and Documentation in the Governance of Indigenous Peoples of Australia', Sites: A Journal of Social Anthropology \& Cultural Studies, vol. 14, no. 1, 2017, pp. 80-105.

27 See Richard Howitt and Jessica McLean, 'Towards Closure? Coexistence, Remoteness and Righteousness in Indigenous Policy in Australia', Australian Geographer, vol. 46, no. 2, 2015, pp. 137-45, p. 143.

28 See Amy McQuire, 'WA Government Deregisters World's Oldest Rock Art Collection As Sacred Site', NewMatilda.com, 30 April 2015. https://newmatilda.com/2015/04/29/ wa-government-deregisters-worlds-oldest-rock-art-collection-sacred-site/

29 Sarah Prout, 'Urban Myths: Exploring the Unsettling Nature of Aboriginal Presence In and Through a Regional Australian Town', Urban Policy and Research, vol. 29, no. 3, 2011, pp. 275-91.

30 K. Bradley, G. Delaney, I. Hammel, C. Melanie, F. Morgan, P. Morrissey, K.L. Rendell, The Oombulgurri Project, School of Culture and Communication, University of Melbourne, Melbourne, 2015. http://hdl.handle.net/11343/112377

31 Benterrak, Muecke and Roe, pp. 245, 248.

32 Ibid., p. 240, emphasis in original.

33 Ibid.

34 Ibid., pp. 243, 244 .

35 Ibid.

36 David McNeill, "Black Magic”, Nationalism and Race in Australian Football', Race \& Class, vol. 49, no. 4, 2008, pp. 22-37, p. 29. According to an official AFL website, Indigenous players currently make up nine per cent of community football players. http://www.aflcommunityclub.com.au/

37 The Stolen Generations describes the Australian state's forced removal of children from Indigenous homes; see Stan Grant and Adam Goodes, 'A Good Man Stands Up: Adam Goodes', Awaken (NITV), 10 September 2015.

38 Andrea Booth and Natalie Ahmat, 'That Adam Goodes War Cry Used a Boomerang Not a Spear: Choreographer', NITV News, 3 August 2015.

39 Jesse Hogan, 'Eddie McGuire: Adam Goodes Should Have Warned Crowd About War Dance', The Guardian, 1 June 2015.

40 There is a long political history of 'aggression' being invoked by those seeking to frame their own actions as retaliations. See Joanna Bourke, Wounding the World: How Military Violence and War-Play Invade Our Lives, Hachette, London, 2014.

41 Adam Goodes quoted in Andrea Booth, 'Racism or Other: What's with the Vitriol Towards Adam Goodes?', NITV News, 30 July 2015.

42 Stan Grant, 'I Can Tell You How Adam Goodes Feels: Every Indigenous Person Has Felt It', The Guardian, 30 July 2015.

43 McNeill, p. 37.

44 Quoted in Booth, 'Racism or Other'.

45 These histories are invoked in Ellen van Neerven, 'Four Grounds,' Next Wave Festival 2016, Melbourne, Victoria, 2017, http://2016.nextwave.org.au/essays/fourgrounds. Last accessed: 8 February 2017. 
46 Ghassan Hage, 'Good White Nationalists: The Tolerant Society as a White Fantasy', in White Nation, Pluto Press, Sydney, 1998, pp. 78-104.

47 Ibid.

48 Benterrak, Muecke and Roe, p. 249, emphasis in original.

49 Waleed Aly, 'Waleed Aly on the Reaction to Adam Goodes', ABC Offsiders, 31 March 2015. http://www.abc.net.au/sport/offsiders/

50 'The NSW Parliament Names Eddie McGuire a "Boofhead", NITV News, 3 June 2015, emphasis added.

51 See Marilyn Frye, 'On Being White: Thinking Toward a Feminist Understanding of Race and Race Supremacy', The Politics of Reality, Crossing Press, Freedom, CA 1983, pp. 110-27; Gabrielle Russell-Mundine, 'Disrupting the White Noise', National Centre for Cultural Competence, University of Sydney, http://sydney. edu.au/nccc/news/white-noise.shtml. Last accessed: 18 March 2018.

52 See Russell-Mundine. 